FACTA UNIVERSITATIS

Series: Architecture and Civil Engineering Vol. 10, Nº 3, 2012, pp. 343 - 352

DOI: 10.2298/FUACE1203343L

\title{
ENERGY EFFICIENCY OF BUILDINGS WITH PHASE-CHANGE MATERIALS *
}

\author{
$U D C$ 697.1:621.315.61=111
}

\author{
Predrag Lukić ${ }^{1}$, Jasmina Tamburić ${ }^{2}$, Dragoslav Stojić \\ University of Niš, Faculty of Civil Engineering and Architecture, Serbia \\ dragoslav.stojic@gmail.com
}

\begin{abstract}
The construction of energy efficient buildings using innovative building materials such as phase change materials, in addition to improving indoor comfort, energy savings and costs, can be achieved by increasing their market value. Because of its ability to absorb and release energy at predictable temperatures, phase change materials are effective in controlling and maintaining the thermal environment in the building. The use of phase changing materials, materials stored latent energy storage is an effective form of heat.
\end{abstract}

Key words: energy efficiency, building materials, phase change materials, energy saving.

\section{INTRODUCTION}

Due to the high consumption of energy in buildings, and due to the highest potential for energy and environmental saving, energy efficiency is nowadays the priority of contemporary architecture and power industry. The action plan for energy efficiency, a series of directives and incentive mechanisms, mandatory energy certification of buildings, indicate the urgent need to reduce energy consumption in buildings, which results in a more comfortable dwelling in buildings, long service life of buildings, which in turn preserves the environment.

Housing stock in our region uses up to do $40 \%$ of total consumed energy (Fig. 1), which significantly more than needed to provide comfort and function. Such wasting of energy significantly contributes to the greenhouse effect. For this reason, saving in energy consumption of the residential buildings can contribute to solving of the global problems such as the climate change and energy safety.

Received December 14, 2012

* Acknowledgement: This research is supported by the Ministry of Science and Technological Development of the Republic of Serbia, within the framework of the Technological Development project No TR36016 for project cycle 2011-2014. "Experimental and theoretical investigation of frames and plates with semi-rigid connections from the view of the second order theory and stability analysis" of the research organization The Faculty of Civil Engineering and Architecture of University of Nis.

${ }^{1}$ PhD Student, ${ }^{2}$ Associate 


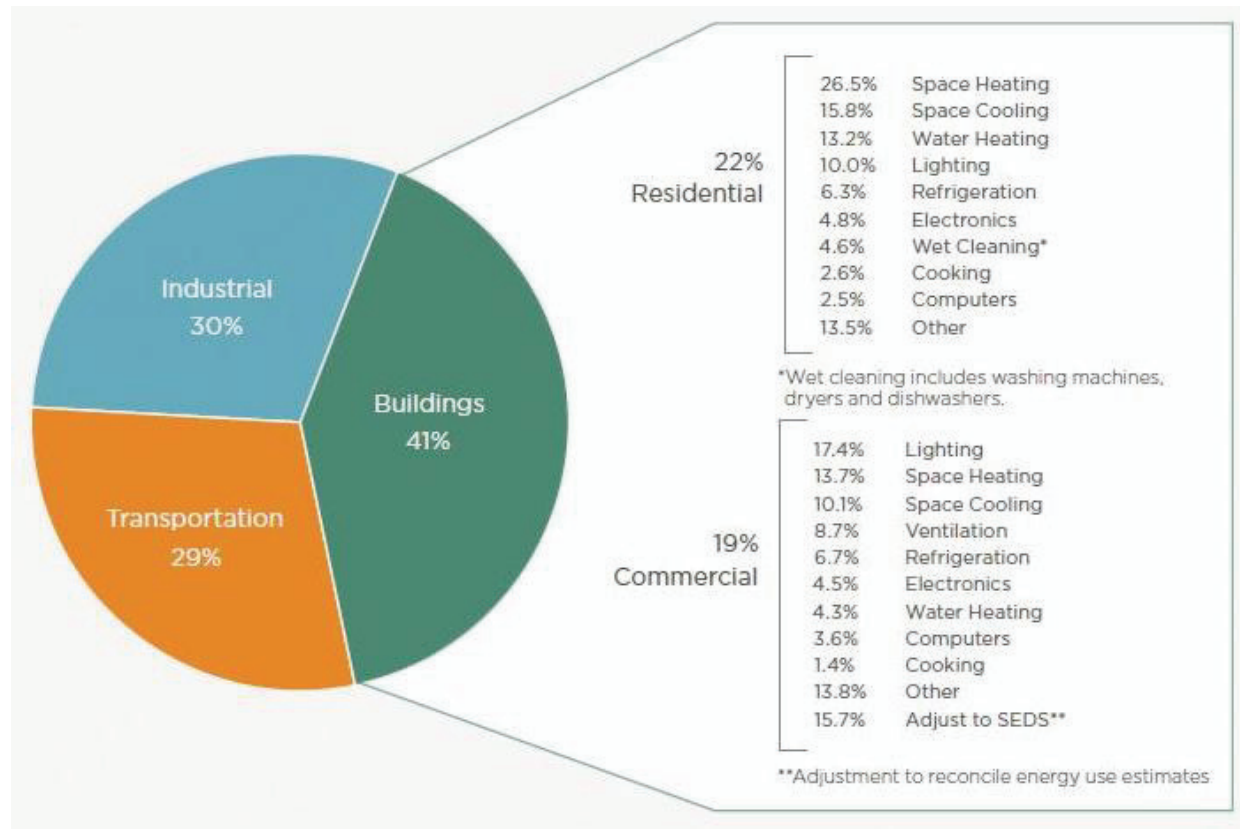

Fig. 1. Energy consumption by sectors expressed in percents

The majority of buildings in the developed countries was built from the conventional building materials: brick and mortar, concrete (with or without steel reinforcement), steel or timber frames for structural components, insulation for reduction of the air conditioning load and plaster walls within the buildings. Even though the insulation provides that different parts of walls have similar thermal conductivity, the thermal mass of the walls, i.e. the amount heat absorbed in order to increase or decrease the temperature can vary greatly. For instance, a concrete wall has a significantly higher thermal mass than a wooden wall in the frame per unit of volume.

In the residential buildings sector is the largest potential for energy saving (min. 22\% of the current energy consumption). The consumption in a building is affected by:

- characteristics of the structure,

- energy joints in the building,

- climate conditions,

- users' habits.

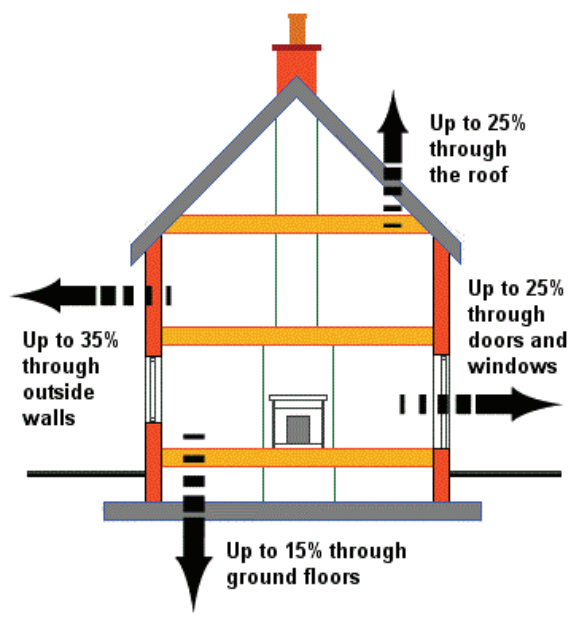

Fig. 2. Heat losses of a building

(Figure 2) provides a presentation of heat losses o a building.

Usage of phase-change materials, as materials which store the latent energy is an efficient way of storing of thermal energy. In the course of change of phase (state of matter), 
the phase-change materials reversibly exchange energy with the environment, storing it in the form of the latent heat, whereby the temperature of the material remains constant. Absorption and emission of energy occur at strictly defined temperatures, dependent on the type of material. Only those phase-change materials which have the phase change close to the temperature comfortable for human dwelling $\left(20-26^{\circ} \mathrm{C}\right)$ are efficient in control and support of the thermal environment in a building. By increasing the capacity of storing energy in the buildings, by installing the phase-change materials, the excess heat can be stored and released later, when need arises.

By applying the phase-change materials, one may reduce the energy consumption with discreet intervention where needed, that is on the exposed external or partition walls, ceilings or floors, by increasing their thermal mass. The characteristics of phase-change materials are determined at the micro level, and occur in the molecular structure of the material, so when implementing these materials one should focus on what they can achieve in their immediate environment in terms of energy. For this reason, the positive effects of phase-change materials, in broad terms, should be identified in respect to the manifestations they trigger in the human environment. Application of phase-change materials in buildings allows usage of thermal energy minimizing the need for heating and thus the energy consumption during winter, and in summer provides protection from the excessive heating of the building which results in reduced power consumption of cooling air conditioning devices.

By installing the phase-change materials in buildings, the most significant energy saving is achieved in the transitional periods between the hottest and coldest seasons, in late spring and summer and late autumn and winter, because they reduce the maximum temperature peaks and valleys equalizing the climate in the building interior.

\section{ApPliCATION OF PHASE-CHANGE MATERIALs In CIVIL ENGINEERING}

In around 30 years the researchers invented the methods of increase of thermal mass of civil engineering structures by incorporating the phase change materials in the building materials. The latent heat required for initiation of the phase change in a material is considerably bigger than the specific heat of the material, e.g. the latent heat of a wooden wall with around $30 \%$ of phase change material is by weight around five times higher than the amount of heat absorbed $\mathrm{b}$ a conventional wooden wall at the temperature change for $5,5^{\circ} \mathrm{C}$. Hence, the phase-change material (PCM) effectively increases the thermal mass of the building material when temperature is increase above or below the transitional temperature of PCM.

The PCMs researched as building materials include organic matter, such as paraffin and salt hydrates. Even though much effort is made to examine wallboards which had PCM, teh floor and ceiling tiles, slab parts, insulation foam panels, gypsum, radiating partitions, cellulose insulation, roll-ups and concrete containing PCM were also examined.

The most of PCMs were evaluated for usage as building material, and they usually change phase from solid to liquid at a temperature which is in the acceptable comfort range for building residents, that is, from $21^{\circ} \mathrm{C}$ to $26^{\circ} \mathrm{C}$. Ideally, the change of phase occurs at a definite temperature, but in practice, the most of PCMs change phase in a range of temperatures. For PCMs on paraffin basis, the range of transitional temperature depends on the purity of material, that is, the higher purity reduces the range [1]. 
In the construction materials, it was first attempted to place the micro-capsules filled with PCM into classic building materials. The success was limited, since the micro-capsules affected the mechanical properties of materials and they needed to be protected from destruction, to prevent leaking. Cutting or drilling through such material was out of the question, which rendered the installing much more complex and expensive. The problems occurred because of the poorer transfer of heat through the material. For all these reasons, the products based on micro-capsules have not seen a market success.

In the meantime, the process of capsule production was simplified and made cheaper, so now micro-encapsulated PCMs are used, or PCMs on special grid mountings, most often already installed in gypsum-cardboard panels or blocks of porous cement.

The micro-capsules have a diameter of several $\mathrm{mm}$ (Figure 3), so there are no problems in installing, cutting and drilling, nor in heat transfer as smaller capsules have larger surface area and they are dispersed throughout the material, so the heat exchange is better, and they can be added in the mix when gypsum-cardboard panels or foam concrete without significant modifications in the production technology.

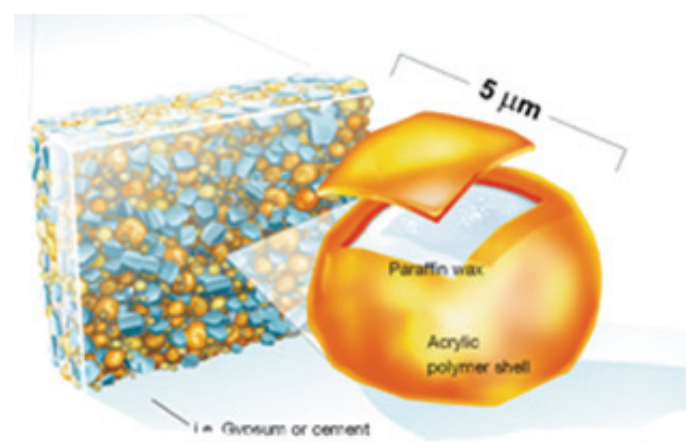

Fig. 3. Microcapsule appearance

\section{PROPERTIES OF PHASE-CHANGE MATERIALS}

Usage of energy efficient technologies based on phase-change materials in reconstruction of existing and construction of new buildings, apart from improvement of interior comfort, saving of energy and money, enhances their market value. Even though these technologies become ever cheaper and profitable through the accelerated development, their usage in civil engineering is limited, due to the lack of knowledge of their changeable properties and dynamic behavior under the external stimuli. The PCMs, in the course of change of phase state reversibly exchange energy with their environment and store it as latent heat, whereby the temperature of the material remains constant. As a result of their property to absorb and emit energy at predictable temperatures, they are very efficient in control and maintaining of thermal ambient in a building. The micro-encapsulated phase change materials with the filling on the basis of paraffin, built into mortars, walls, gypsum boards, glazing systems, ceilings or floors, provide passive conditioning of internal areas and reduction of energy consumption in buildings. Thermal characteristics of the existing buildings can also be improved by increasing their heat storing mass, by 
installing the PCM products which results in decrease of use of energy obtained from the combustion of fossil fuels emission of $\mathrm{CO} 2$ into the atmosphere.

Phase-change materials reversibly store/release heat energy, as a response to energy changes in their surroundings. All the materials can exist in various physical states: gaseous, liquid and solid, which are known as phases. The temperature changes or pressure in the environment cause breaking of molecular bonds in the structure of the material, which leads to the change of physical state (phase) of material, the so-called phase change. Phase change processes include absorption, storing and release of a definite quantity of energy in the form of the latent heat, which depends on the molecular structure. In order for the material to change from the solid into gaseous state, a certain amount of heat energy must be absorbed. When the material turns back from the gaseous state into liquid and then into solid state, that energy is released into the environment. These processes are reversible, and phase-change materials can undergo an unlimited number of cycles, with no degradation. The phase changes from the solid into liquid or from liquid into gaseous and vice versa occur at precisely determined temperatures, which are different for different materials. This means that absorption or emission of energy can be defined in advance by combining materials with different melting points [2].

At a certain, material-dependent temperature, these materials are crystallized with the simultaneous release of the same quantity of heat energy, which was earlier, at a higher temperature, absorbed and stored. Initially, phase-change materials behave as other materials, they warm-up as a consequence warming by the ambient temperature until it reaches the temperature where they change phase, the so-called melting point (Figure 4), absorbing a certain amount of heat, without increasing their own temperature any further. When the ambient temperature surrounding the phase-change material decreases, it starts to solidify, releasing its latent heat. While a phase-change material absorbs and emits heat during its phase change, it retains almost constant temperature, so these materials are very efficient in the range of tolerance for human comfort, from $20^{\circ} \mathrm{C}$ to $26^{\circ} \mathrm{C}$ (Figure 5) [3].

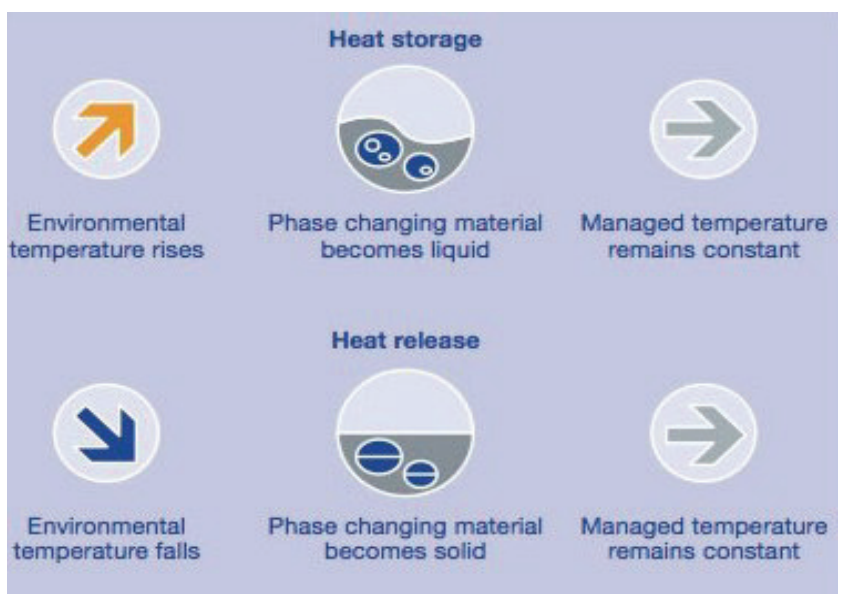

Fig. 4. How phase-change materials operate 


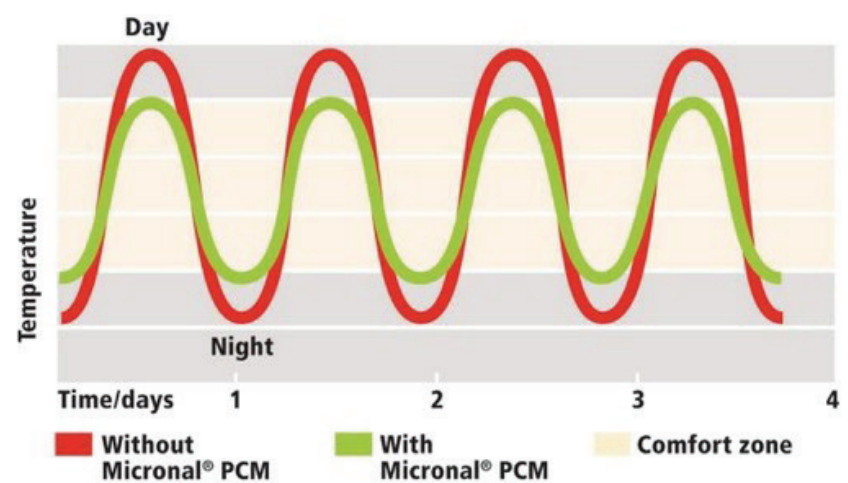

Fig. 5. Presentation of active conditioning control - PCMs reduce temperature maximums

Phase-change materials can be divided into three basic groups (Table 1), while the most frequent in civil engineering are [4] :

Organic

- Paraffin and paraffin mixtures

Inorganic

- Hydrated salts and their mixtures

- Silicates.

Table 1. Classification of phase-change materials

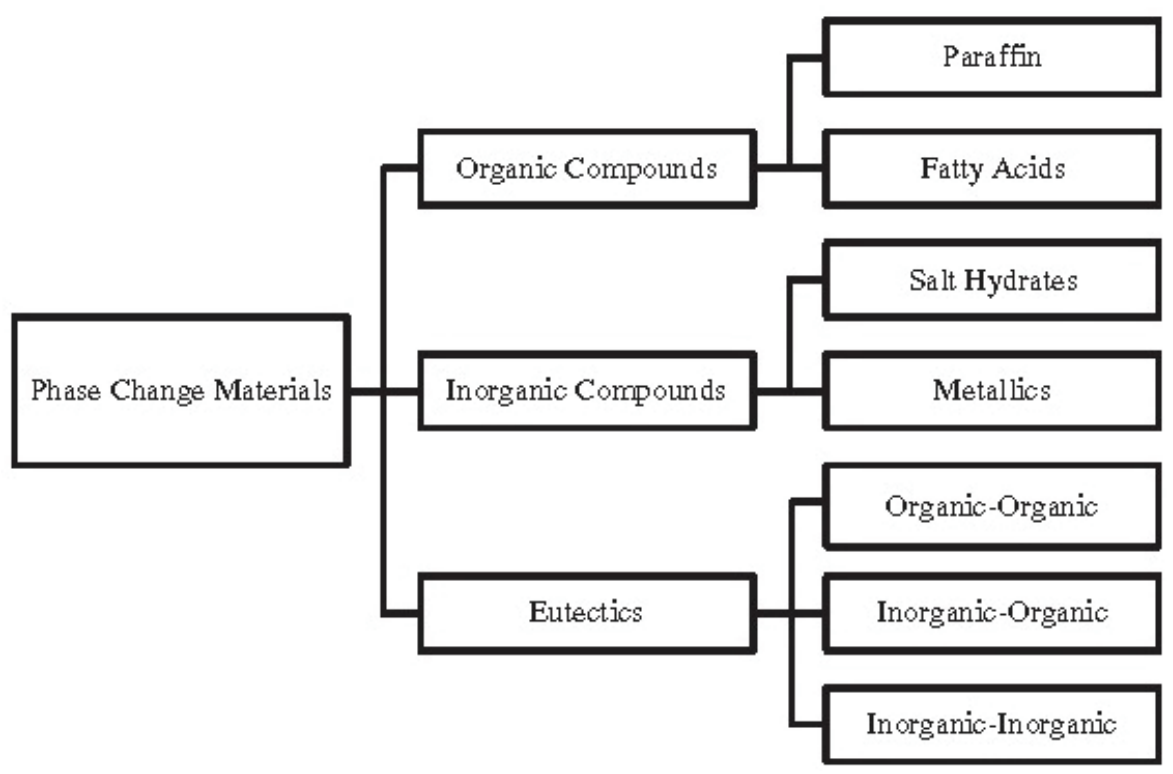


Mineral waxes, including paraffin, are obtained from petroleum and natural minerals. Organic phase-change materials are expensive and store (release) an average amount of heat per volume unit. Most of them are inflammable in nature.

Inorganic phase-change hydrated salts (Figure 6) are more stable, do not pollute the environment, are not toxic and are bio-degradable. They are more suitable for installing in building materials than the organic ones, as they have a more favorable heat transfer and lower flammability. Yet, they are not stable in water environments and vapors, and they need to be protected from the negative environmental impacts.

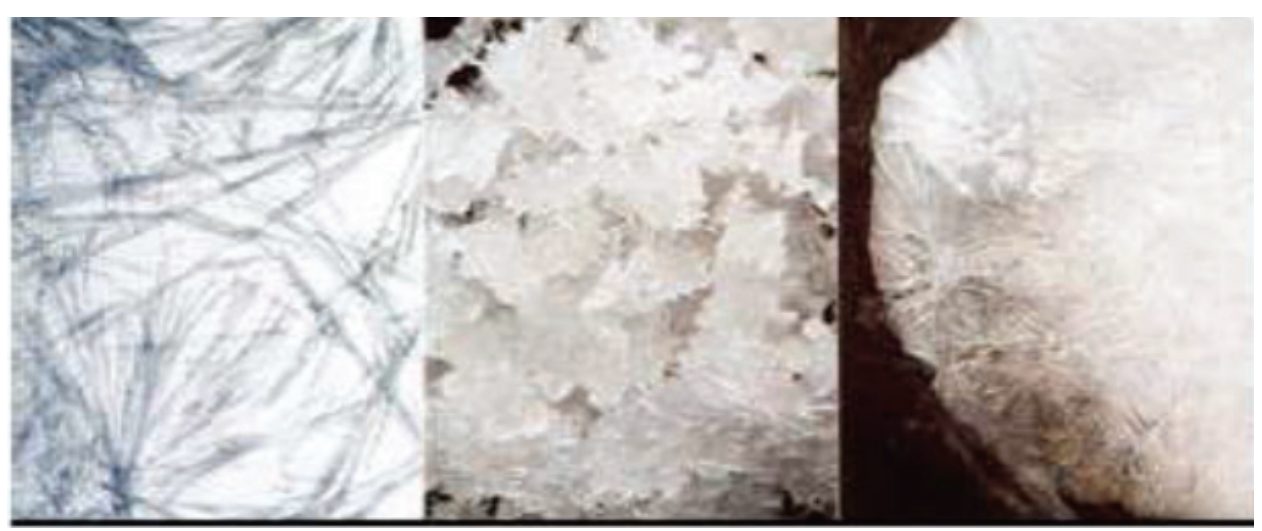

Fig. 6. Microscope photographs of the crystals of hydrated salts before and after warming-up

Silicates are used as a carrying medium for installing of various phase-change materials, in a proportion $40 \%$ to $60 \%$ with a composite materials (gypsum, cement). The practical challenge of finding a safe way of installing and storing of paraffin, due to its flammability, in other building materials is solved by micro-encapsulation.

Microencapsulated phase-change material (Figure 7) is created by insertion of microscopically small droplets of paraffin into indestructible acrylic polymer shells [5].

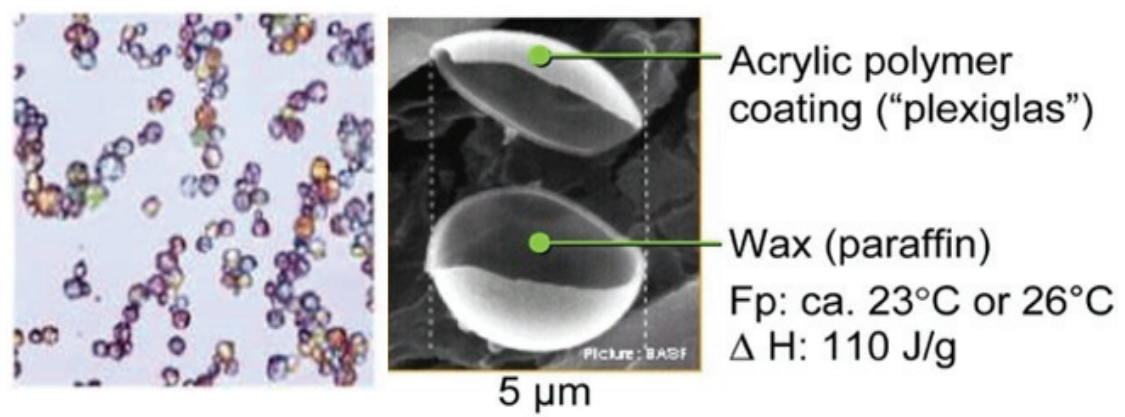

Fig. 7. Microencapsulated phase-change material 


\section{ENCAPSULATION OF PHASE-CHANGE MATERIALS}

The practical challenge of finding a safe way of installing and storing of paraffin, due to its flammability, in other building materials is solved by micro-encapsulation (Figure 8). By micro-encapsulation the small round or tubular particles of material are enclosed into a thin polymer film of high molecular weight. Particles enclosed in such manner can be installed in any matrix, compatible with encapsulated film.

The microencapsulated phase-change material is created by insertion of microscopically small droplets of paraffin into indestructible acrylic polymer shells, which can withstand drilling and cutting, and paraffin cannot leak out from its impregnable capsule. These micro-capsule, resistant to mechanical damage, meet all the building standards and environment protection requirements, so they can serve either directly as heat exchangers for passive conditions, or can be installed as components in other building elements such as the walls, floors or ceilings.

By macro-encapsulation the phase-change material is inserted in a form such as tubes, balls, bags or panels. The phase-change materials are not expensive themselves, but their packing and processing in order to achieve reliable and consistent performances of the material for usage, make the end price of the product higher.
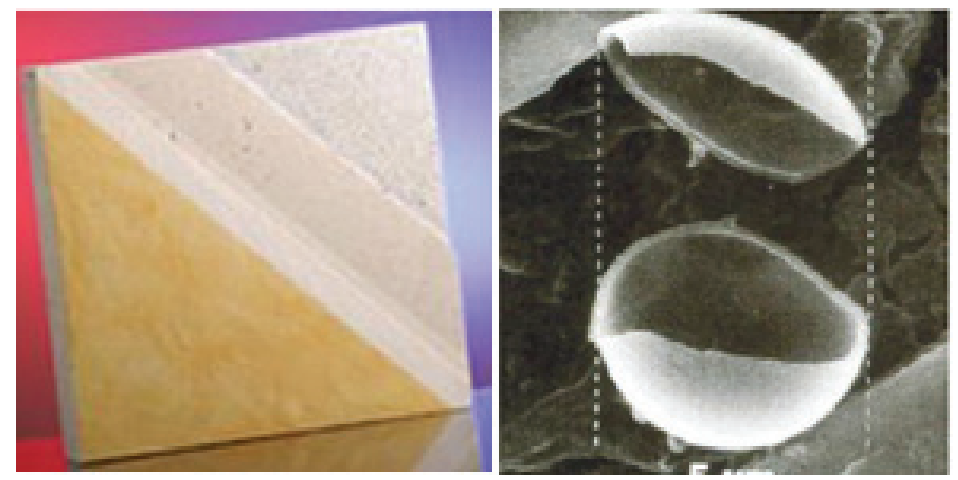

Fig. 8. Thin polymer shells filled with paraffin resin

\section{ENERGY SAVING POTENTIAL}

Due to its high thermal mass, the phase-change material can bring about significant reduction in cooling load at the beginning of day when the structural components containing PCM are in solid state. When the external temperatures rise and the solar energy hits the building, the heat flows through the building and the PCM absorbs it, as well as internal heat sources (e.g. lighting, office equipment, people). In this way, until sufficient heat enters the structural component and make it change the PCM phase, the component remains at the phase-change temperature (or in the temperature range) of PCM. If the internal and external temperature are reduced below the phase change temperature before the PCM completely changes the phase, the heat will be released from PCM. For this reason, the components containing PCM can attenuate the variations of internal temperature, reduce cooling load and significantly reduce or delay the load for the later period of the 
day. The impact of PCM on cooling and heating loads of buildings varies for different building types, that is, the PCMs have bigger impact in the light structure buildings, such as the frame buildings or mobile motor homes. The climate also affects the energy saving of PCM, since in temperate climate, where the external temperature often varies around the transitional temperature of PCM (especially in the night), the energy savings will be significantly larger than in the climates where temperatures during the cold season remain above or below the transitional temperature. The PCM is particularly efficient in the areas with the temperate climate with large daily variations and low humidity levels, where overnight ventilation can be used for cooling and re-solidification of PCM without creating the dampness problems. Evaluations of the energy saving potential of PCM in building materials are limited. One study was devoted to simulation of building components containing PCM. The simulations of a concrete wall $305 \mathrm{~mm}$ thick, in Dayton, Ohio, containing $10 \%$ of PCM (average transitional temperature around $26^{\circ} \mathrm{C}$ ) resulted in $13 \%$ reduction of annual cooling load through the wall. The simulation of a steel roof with 2 insulating panels with $28 \%$ of weight of the same PCM showed that the annual cooling loads could be reduced by air circulation through that structural component for $14 \%$. The frame wall simulations showed that gypsum boards with assimilated PCM (also up to $28 \%$ ) reduced the annual cooling load through the wall for around $9 \%$. The appropriate simulation of the load of the whole house yielded the result showing that walls - again with $28 \%$ of PCM - reduce the cooling loads for around $4 \%$. When the method of overnight air circulation of internal areas with cool external air is implemented, the reduction of annual cooling load was much higher $-17 \%$. In all the cases the saving of heating energy was significantly lower or negligible [6].

In general, the available data suggest the initial assessment that PCM in building materials can reduce the annual consumption of cooling energy in residential buildings for as much $10 \%$, but that they do not significantly reduce the heating energy consumption. Similarly, reduction of $10 \%$ for a half of commercial building is possible. Many commercial buildings already have a significant building mass, and usually have higher interior heat generation than the residential buildings. Supposing such level of reduction of usage of energy for cooling loads the annual national savings in primary energy (total energy used by the end user, including the energy used for production and transmission of electric power) can amount to approximately 0,4 quad if the PCM technology is implemented. Apart from that, new analyses for the purpose of a better understating of energy saving potential of building materials with PCM are necessary [7].

\section{CONCLUSION}

Usage of energy efficient technologies based on phase-change materials in reconstruction of existing and construction of new buildings, apart from improvement of interior comfort, saving of energy and money, enhances their market value. The products of phase-change materials can be used in existing and new buildings for the purpose of improving their thermal characteristics, by increasing their heat-storing mass.

Improvement of thermal characteristics in buildings, using the phase-change material depends on the type of used material, its melting temperature and the percentage to which it is mixed with the conventional material. By optimizing these parameters, the capacity of 
heat storage in buildings is increased, which enhances the interior comfort, by reducing the internal air temperature frequency, so that the interior temperature is closer to the desired one for longer time periods.

The phase-change materials will primarily have to be reliable long time and to have the properties such as strength and durability and ease of usage and installing in the classic building materials, or otherwise the designers and contractors would not use a new and untried product. Another property they must have is the stability of transitional temperatures of PCM, e.g. the transitional temperature of one PCM plus around $3^{\circ} \mathrm{C}$ in the period of over 10 years [3].

The number of researches in this area increases each year. The quality results which will ensue, and the increasing funding of these researches, increasing interest by the industry and the increasing awareness of the necessity to preserve nature will doubtlessly lead to improvement of technology and wide application of phase-change materials.

\section{REFERENCES}

1. Dr Kurt Rota, dr Detelf Westphalen, dr James Brodrick., Tehnologija fazno promenljivih materijala za građevinarstvo, Departman of Energy, SAD. (2007), str. 31-33.

2. IEA, Annex 17: Advanced Thermal Energy Storage through Phase Change Materials and Chemical Reactions - Feasibility Studies and Demonstration Projects, International Energy Agency Implementing Agreement on Energy Conservation through Energy Storage, Final Report, 2005.

3. Kissock, J. K., et al., Testing and simulation of phase change wallboard for thermal storage in buildings, Proceedings of the ASME International Solar Energy Conference, 1998.

4. Atul Sharma, V.V. Tyagi, C.R. Chen, D. Buddhi, Review on thermal energy storage with phase changematerials and applications, Renewable and Sustainable Energy Reviews 13, 2009.

5. Vučeljić S., Analiza mogućnosti povećanja energetske efikasnosti zgrada primenom fazno promenljivih materijala, Arhitektonski fakultet Univerziteta u Beogradu, Beograd, 2009.

6. Schwartz, Mel. (2002), Smart materials - Encyclopedia of materials, parts and finishes. CRC Press LLC, USA, New York, pp. 855.

7. Kludhair A. M., Farid M. M., A revive on energy conservation in building applications with thermal storage by latent heat using phase change materials, Energy conversion and Management 45, 2004.

\section{ENERGETSKA EFIKASNOST ZGRADA PRIMENOM FAZNO PROMENLJIVIH MATERIJALA}

\section{Predrag Lukić, Jasmina Tamburić, Dragoslav Stojić}

Izgradnjom energetski efikasnih zgrada upotrebom inovativnih građevinskih materijala kao što su fazno promenljivi materijali, pored unapređenja unutrašnjeg komfora, uštede energije $i$ troškova, može se postići i povećanje njihove tržišne vrednosti. Zbog svojih sposobnosti da apsorbuju $i$ oslobađaju energiju na predvidivim temperaturama, fazno promenljivi materijali su efikasni u kontroli $i$ održavanju toplotnog okruženja u zgradi. Upotreba fazno promenljivih materijala, kao materijala koji skladišti latentnu energiju, predstavlja efikasn vid čuvanja toplotne energije.

Ključne reči: energetska efikasnost, građevinski materijal, fazno promenljivi materijal, ušteda energije 